\title{
COVID-19 causing acute deterioration of interstitial lung disease: a case report
}

\author{
Mohamed Rafi Kathar Hussain, N. Kulasekaran, A. M. Anand and Padma Reka Danassegarane*
}

\begin{abstract}
Background: Interstitial lung disease (ILD) comprises a heterogeneous group of disorders characterized by multifocal diffuse lung involvement. Similarly, COVID-19 has varied multispectral organ involvement. Patients with underlying ILD and coexistent COVID-19 infection may lead to an acute blow to the already deceased lung.

Case presentation: A 58-year-old man presented with fever and cough with expectoration for the past 4 days associated with breathlessness. He was a smoker and alcoholic for the past 20 years. His saturation was low in room air around $84 \%$ and improved to $98 \%$ with $10 \mathrm{l} /$ min of nasal oxygen. Further investigation shows acute deterioration of ILD.

Conclusion: COVID-19 infection has a spectrum of manifestations. Acute deterioration of ILD is rarely reported in the literature. Etiology should be investigated further.
\end{abstract}

Keywords: COVID-19, Interstitial lung disease, Computerized tomography, Acute deterioration

\section{Background}

Interstitial lung disease (ILD) comprises a complex group of disorders characterized by multifocal diffuse lung involvement. Likewise, COVID-19 infection had a different pattern involvement with a multi-spectrum of disease exemplar. Patients with ILD after COVID-19 infection may lead to an acute blow to the already deceased lung. COVID-19 is a global pandemic caused by severe acute respiratory syndrome coronavirus 2 (SARSCoV2). Post infective pulmonary fibrosis is common after any viral pneumonia [1]. The most common pulmonary imaging manifestation of the coronavirus is ground-glass opacity (GGO) and consolidation which is usually bilateral, sup-pleural, and peripheral $[2,3]$. The clinical presentation of the coronavirus ranges from mild asymptomatic to severe infection. The majority of mild to moderate illness cases are completely recovered whereas a small proportion of severely infected cases remain in hypoxemia, despite adequate medical management [4]. COVID-19 infects all people irrespective of

\footnotetext{
*Correspondence: rekha7718@gmail.com

Department of Radio Diagnosis, Sri Manukula Vinayagar Medical College, Puducherry, India
}

\section{Springer Open}

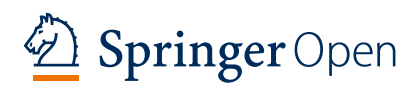

age, gender, race, and those with or without comorbidities like ILD.

\section{Case presentation}

A 58-year-old man presented with complaints of fever and cough with expectoration for the past 4 days associated with breathlessness. He was a known smoker and alcoholic for the past 20 years. He is not a known diabetic or hypertensive. The patient was diagnosed to be RT-PCR positive for coronavirus 45 days before and treated in an outside hospital for COVID-19 infection. Repeat RT-PCR in our hospital, at the time of admission, was found to be negative. He was a known case of ILD of combined pulmonary fibrosis and emphysema (CPFE) type on irregular treatment. He was admitted to an outside hospital for treatment of COVID-19 infection and discharged. Data regarding this outside hospital stay and treatment undertaken was not available. CT imaging done during this stay could not be retrieved.

On examination, there was no pallor, icterus, cyanosis, clubbing, or lymphadenopathy. His blood pressure was $130 / 90 \mathrm{~mm} \mathrm{Hg}$, and his respiratory rate was 26 breaths/ min. Heart rate was $130 \mathrm{bpm}$. His saturation was low in
๑) The Author(s). 2021 Open Access This article is licensed under a Creative Commons Attribution 4.0 International License, which permits use, sharing, adaptation, distribution and reproduction in any medium or format, as long as you give appropriate credit to the original author(s) and the source, provide a link to the Creative Commons licence, and indicate if changes were made. The images or other third party material in this article are included in the article's Creative Commons licence, unless indicated otherwise in a credit line to the material. If material is not included in the article's Creative Commons licence and your intended use is not permitted by statutory regulation or exceeds the permitted use, you will need to obtain permission directly from the copyright holder. To view a copy of this licence, visit http://creativecommons.org/licenses/by/4.0/. 
room air around $84 \%$ and improved to $98 \%$ with $10 \mathrm{l} /$ min of nasal oxygen. Lab parameters reveal normal random blood glucose. Serum urea and blood creatinine were within normal limits. The total count was reduced to 3000 indicating leukocytopenia. His eosinophil counts were within normal limits.

On admission, HRCT thorax was done and showed diffuse interstitial thickening and ground-glass opacities in bilateral lung parenchyma associated with diffuse emphysematous changes and bullae predominantly in the bilateral upper lobes, consistent with interstitial lung disease (Fig. 1). The patient was started on oral methylprednisolone. Despite adequate medical management, the patient was persistently dependent on oxygen supplementation with continuing symptoms. His stool examination revealed Strongyloides infection, and hence he was administered with two doses of $12 \mathrm{mg}$ ivermectin. Pulmonary Strongyloides was not suspected because the blood eosinophil count was within normal limits. Treatment continued along with the oxygen supplementation for ILD.

Repeat CT thorax after a month showed a marked increase in emphysematous and bullous changes in the bilateral upper lobes when compared to the previous $\mathrm{CT}$ (Fig. 2). There were also bilateral subpleural fibrotic bands are seen in the basal segments of the bilateral lower lobes. Because of post-COVID-19 pulmonary fibrosis, he was started on pirfenidone. The patient showed mild improvement over the next few days and was discharged home requiring $4 \mathrm{l} / \mathrm{min}$ of oxygen supplementation. And the patient was asked to have strict follow-up and close monitoring.

One week after discharge, the patient was again rehospitalized due to worsening dyspnea and increased cough. Chest radiographs was done and showed serial significant progression of emphysematous changes (Fig. 3). The patient was again started on methylprednisolone for flaring up of interstitial lung disease. Despite starting on steroids and with $10 \mathrm{l} / \mathrm{min}$ of nasal oxygen, his condition worsened and ultimately requiring non-invasive ventilation and hence transferred to medical ICU for vigorous monitoring. Although many factors like smoking and alcohol can also cause acute deterioration of ILD, in the present clinical contest of recent COVID-19 infection, all other factors are excluded. He has been diagnosed as a case of a post-COVID-19 acute deterioration of ILD. At the time of writing this article, the patient was in ICU under oxygen support.

\section{Discussion}

The acute stage of lung infection in COVID-19 presents with ground glass opacities whereas the late-stage manifest as crazy pavy patterns and subpleural peripheral fibrotic bands. Some COVID-19 infection leading to progressive fibrotic lung disease was also reported in the literature. Anti-fibrotic drugs like pirfenidone and nintedanib in some cases had been proven to be beneficial [5]. The pathogenesis of post-viral pulmonary fibrosis is most likely due to the release of matrix metalloproteinase causing epithelial and endothelial injury [6]. Vascular endothelial growth factor, interleukin-6, and TNF- alpha are also being implicated in pulmonary fibrosis [7]. There are many etiologies for lung fibrosis; one of the causes is interstitial lung disease (ILD).

ILD is a heterogeneous group of disorders that are classified into four types: (a) ILD with a known cause like rheumatoid arthritis, asbestosis, connective tissue disorders, and hypersensitive pneumonitis; (b) idiopathic interstitial pneumonia (IIP) like idiopathic pulmonary fibrosis, nonspecific interstitial pneumonia (NSIP), respiratory bronchiolitis associated ILD (RB-ILD), desquamative interstitial pneumonia (DIP), and acute interstitial pneumonia; (c) granulomatous ILD—sarcoidosis and silicosis; and (d) others include Langerhans cell histiocytosis (LCH) and lymphangioleiomyomatosis [8]. The common patterns of findings in ILD include a combination of reticulation, ground-glass opacities, honeycombing, traction bronchiectasis, nodules, and thickening of interlobular septa [9].
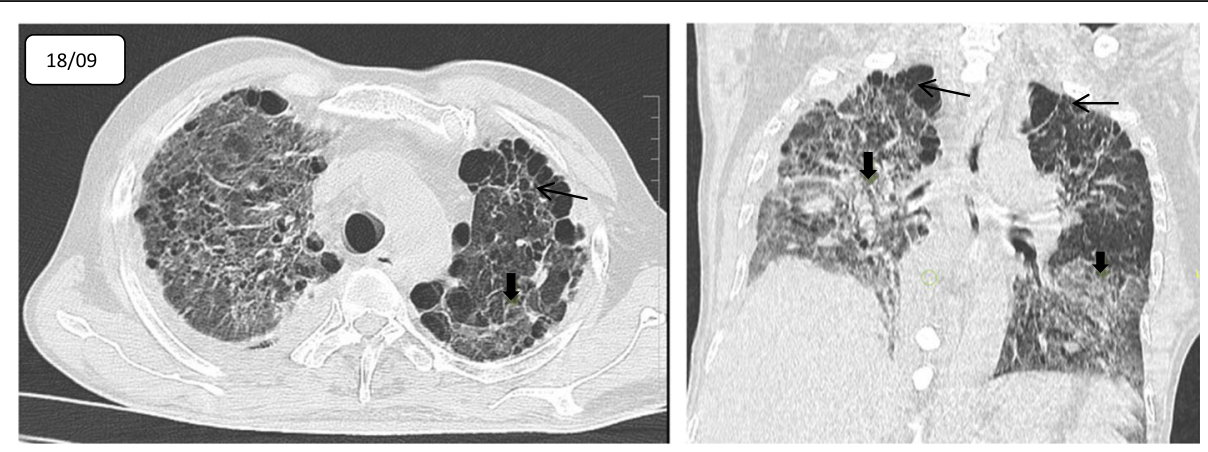

Fig. 1 a, b An initial HRCT axial and coronal section shows diffuse ground glass opacities and reticular interstitial thickening (solid black arrow) with emphysematous changes and bulla (line arrow) in bilateral lung fields 

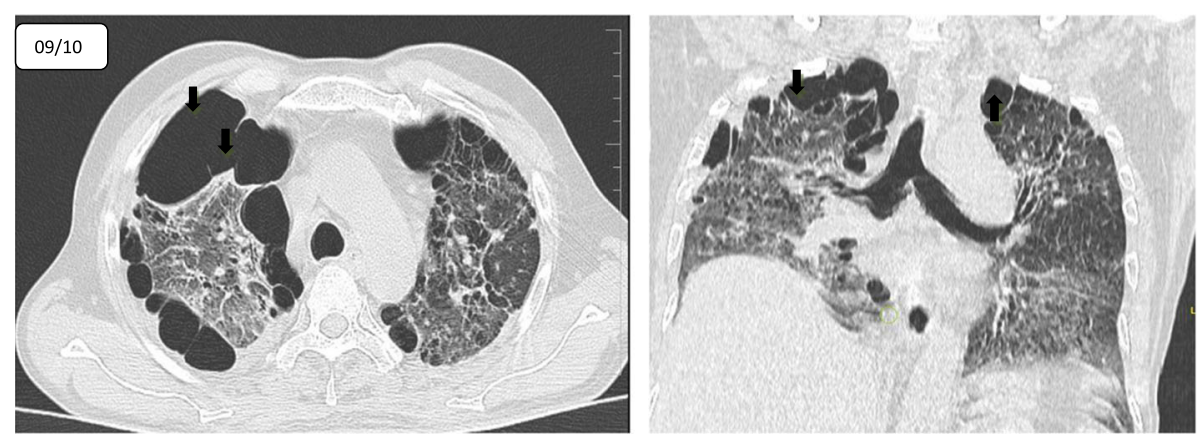

Fig. 2 a, b Repeat HRCT after 1 month axial and coronal sections shows marked increase in emphysematous and bullous changes (black arrow) with reticular thickening and ground glass opacities

The most common idiopathic interstitial pneumonia includes usual interstitial pneumonia (UIP) and NSIP. UIP has typical findings of reticulation, bilateral subpleural symmetrical basal distribution of honeycombing [10]. The key finding in NSIP includes bilateral symmetrical ground-glass opacities in lower lobe predominance with subpleural sparing. Overtime, GGO can be replaced by reticulation [11]. The cardinal features of RB-ILD include centrilobular nodules, GGO, and smooth thickening of interlobular septa, distributed in the upper lobes. The imaging features of desquamative interstitial pneumonia are GGO in the mid and lower zones [8]. Smoking-related ILD includes RB-ILD, LCH, DIP, and combined pulmonary fibrosis with emphysema (CPFE). CPFE is characterized by the co-existence of UIP/NSIP with emphysema in smokers. The emphysematous changes in CPFE are often predominant in the upper zone.

The co-existence of interstitial lung disease and COVID-19 has been reported, and it has been postulated that patients with COVID-19 have an increased risk for developing interstitial lung disease [12]. In patients with preexisting ILD, COVID-19 infection has led to acute exacerbation of underlying ILD. The criteria for ILD exacerbation include subacute worsening of dyspnea and hypoxemia, new pulmonary infiltrates on imaging, and absence of pulmonary emboli, cardiac failure, and other non-pulmonary causes. Surgeries, aspiration of gastric contents, infection, and other factors have also been postulated for ILD exacerbation [13].

ILD renders the host susceptible to viral infection, although the exact etiology is unknown [14]. ILD exacerbation has the worst prognosis [15]. Patients with ILD exacerbation are treated with corticosteroids/other immunosuppressants. It was presumed that if the steroid is given to patients with COVID-19, it decreases the resistance against the virus [13]. To date, there are no clear data to support this fact. A recent study postulated that steroids were likely to be safe and beneficial in patients with severe respiratory disease [16]. In a case-control study by Esposito et al., patients with ILD in advanced age has increased the odds of the worse outcome in COVID-19 patients with underlying ILD [17].

\section{Conclusion}

In this current pandemic scenario, COVID-19 is causing major mortality and morbidity in the entire world. COVID-19 infection in the preexisting ILD patient causes acute aggravation of lung changes in imaging and clinical deterioration. And this needed further research. ILD is the chronic lung condition of the variable progressive poor prognosis. COVID-19 infection on ILD patients is like whipping the already tired horse which will unquestionably lead to increased mortality and morbidity.

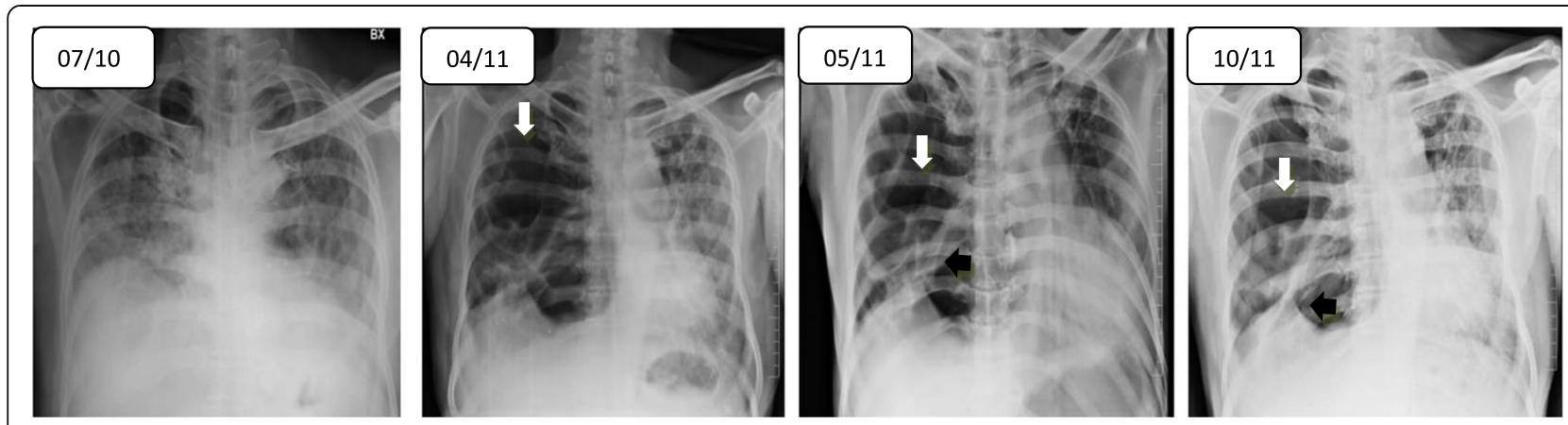

Fig. 3 a-d Consecutive chest x-ray PA view shows progressive increase in lucencies in the right hemithorax (white arrow) with fibrotic changes (black arrow) and mediastinal shift towards the left 


\section{Abbreviations}

ILD: Interstitial lung disease; HRCT: High-resolution computed tomography; SARS-CoV2: Severe acute respiratory syndrome coronavirus 2; IIP: Idiopathic interstitial pneumonia; RB-ILD: Respiratory bronchiolitis-associated ILD; GGO: Ground glass opacities; DIP: Desquamative interstitial pneumonia; CPFE: Combined pulmonary fibrosis with emphysema; UIP: Usual interstitial pneumonia; NSIP: Nonspecific interstitial pneumonia; LCH: Langerhans cell histiocytosis

\section{Acknowledgements}

Nil.

\section{Authors' contributions}

Dr. MR KH (1st author 80\%) collected the data, provided the image and concept, and supported in writing the paper. Dr. KN (2nd author 10\%) helped in supervising the paper. Dr. A AM (3rd author 10\%) had provided the grammatical support in writing the paper. Dr. PD and all authors had collected the information regarding the case and written the manuscript. The authors read and approved the final manuscript.

\section{Funding}

Nil.

\section{Availability of data and materials}

Available.

\section{Ethics approval and consent to participate}

Ethical approval is not obtained, since it is a retrospective case report study. Written consent had been obtained from the participant for participation.

\section{Consent for publication}

Written consent had been obtained.

\section{Competing interests}

Nil.

Received: 27 November 2020 Accepted: 1 February 2021

Published online: 08 February 2021

\section{References}

1. Das KM, Lee EY, Singh R, Enani MA, Al Dossari K, etal (2017) Follow-up chest radiographic findings in patients with MERS-CoV after recovery. Indian J Radiol Imaging 27:342-349

2. Bernheim A, Mei X, Huang M, Yang Y, Fayad ZA, Zhang N, Diao K, Lin B, Zhu X, Li K, Li S (2020 Feb) Chest CT findings in coronavirus disease-19 (COVID-19): relationship to duration of infection. Radiology 20:200463

3. Shi H, Han X, Jiang N, Cao Y, Alwalid O et al (2020) Radiological findings from 81 patients with COVID-19 pneumonia in Wuhan, China: a descriptive study. Lancet Infect Dis 20:425-434

4. Guan WJ, Ni ZY, Hu Y, Liang WH, Ou CQ, He ZX et al (2020) Clinical characteristics of coronavirus disease 2019 in China. N Engl J Med 382: $1708-1720$

5. George P, Wells A, Jenkins RG (2020) Pulmonary fibrosis and COVID-19: the potential role for antifibrotic therapy. Lancet Respir Med 8:807-815

6. Collins BF, Raghu G (2019) Antifibrotic therapy for fibrotic lung disease beyond idiopathic pulmonary fibrosis. Eur Respir Rev 28:190022

7. Tale S, Ghosh S, Meitei SP, Kolli M, Garbhapu AK, Pudi S (2020) Post-COVID19 pneumonia pulmonary fibrosis. QJM 113:837-838

8. Desai SR, Prosch H, Galvin JR (2019) Plain film and HRCT diagnosis of interstitial lung disease. In: Diseases of the Chest, Breast, Heart, and Vessels 2019-2022. Springer, Cham, pp 37-45

9. Hansell DM, Bankier AA, Macmahon $\mathrm{H}$ et al (2008) Fleischner society: glossary of terms for thoracic imaging. Radiology 246:697-722

10. Raghu G, Collard HR, Egan JJ et al (2011) An official ATS/ERS/JRS/ ALAT statement: idiopathic pulmonary fibrosis: evidence-based guidelines for diagnosis and management. Am J Respir Crit Care Med 183:788-824

11. Flaherty KR, Martinez FJ, Travis W et al (2001) Nonspecific interstitial pneumonia (NSIP). Semin Respir Crit Care Med 22:423-434

12. Southern BD (2020) Patients with interstitial lung disease and pulmonary sarcoidosis are at high risk for severe illness related to COVID-19. Cleve Clin
J Med. https://doi.org/10.3949/ccjm.87a.ccc026. Epub ahead of print. PMID: 32409436.

13. Fonseca M, Summer R, Roman J (2021) Acute Exacerbation of Interstitial Lung Disease as a Sequela of COVID-19 Pneumonia. Am J Med Sci 361(1): 126-129

14. Britto CJ, Brady V, Lee S, Dela Cruz CS (2017) Respiratory viral infections in chronic lung diseases. Clin Chest Med 38:87-96

15. Ryerson CJ, Collard HR (2014) Acute exacerbations complicating interstitial lung disease. Curr Opin Pulm Med 20:436-441

16. Ye Z, Wang Y, Colunga-Lozano LE, Prasad M, Tangamornsuksan W, Rochwerg B et al (2020) Efficacy and safety of corticosteroids in COVID-19 based on evidence for COVID-19, other coronavirus infections, influenza, community-acquired pneumonia, and acute respiratory distress syndrome: a systematic review and meta-analysis. CMAJ 192:E756-E767

17. Esposito AJ, Menon AA, Ghosh AJ, Putman RK, Fredenburgh LE, El-Chemaly SY, Goldberg HJ, Baron RM, Hunninghake GM, Doyle TJ (2020) Increased odds of death for patients with interstitial lung disease and COVID-19: a case-control study. Am J Respir Crit Care Med 202:1710-1713

\section{Publisher's Note}

Springer Nature remains neutral with regard to jurisdictional claims in published maps and institutional affiliations.

\section{Submit your manuscript to a SpringerOpen ${ }^{\circ}$ journal and benefit from:}

- Convenient online submission

- Rigorous peer review

- Open access: articles freely available online

High visibility within the field

- Retaining the copyright to your article

Submit your next manuscript at $\boldsymbol{\nabla}$ springeropen.com 